\title{
RESEARCH-ORIENTED PRACTICAL PROBLEM SOLVING AS A LEARNING GOAL FOR THESIS COURSES
}

\author{
Ilia Bider and Paul Johannesson \\ DSV, Stockholm University, Sweden
}

\begin{abstract}
The paper is devoted to the topic of introducing practically oriented thesis writing in the Department of Computer and Systems Sciences of Stockholm University. The paper considers both legal and practical aspects of introducing practically oriented thesis. The material is based partly on the literature study, and partly on the experience of supervising practically oriented BS and MS thesis in the department. The research presented in this paper is of the Action Research type. The paper introduces a rough classification of practically oriented thesis, and discusses problems that need to be solved, such as proper disposition, grading, and method-related courses.
\end{abstract}

\section{KEYWORDS}

Dissertation, Thesis, Education, Information Systems, Problem Solving

\section{BACKGROUND AND MOTIVATION}

The paper reports on ongoing practical and research work at the Department of Computer and Systems Sciences (abbreviated to DSV in Swedish) with several Information Technology (IT) and Information Systems (IS) related Bachelor and Master programs (not counting Doctoral programs). The work aims at facilitating our students to acquire skills of using contemporary research for solving practical problems. The needs for these skills arise from the fact that the majority of our students, both from BS and MS programs, pursue a professional career in private, non-profit or public sector after their graduation; only a small minority chooses an academic carrier. For the university in general and DSV in particular, it is important that the graduates get lasting scientific knowledge useful for their future practice. Otherwise, there is a risk that all scientific theories they studied will be soon and well forgotten.

That there actually are needs to give our students theoretical knowledge useful for practice have been confirmed in a recent survey conducted among our alumni. A number of students forwarded complaints that the theories they learned were not connected to practice, and wished this connection to be established. Some complaints were even more serious: some students stated that if they had had a chance to make their choice once more, they would have chosen a professional education, rather than an academic one.

In regards to our goal of facilitating students to acquire skills for research-oriented problem solving, two questions need to be answered:

1. What should be taught to the students, e.g. which kind of theories and methods?

2. How should it be taught, e.g. in which kind of courses?

In regards to the first question, we refer to the work of (Lee, 2010). Written in 2010, it gives a retrospective view on the IS discipline in the previous 25 years and tries to draft its path for the next 25 years (a third part of which has already passed). The main conclusion of this article is that there is a discrepancy between what IS is trying to achieve in the real world and in the university world. In the real world, IS is trying to establish itself as a profession based on the science of artificial, in the sense of (Simon, 1969). In the university world, however, IS is trying to establish itself as a discipline based on the natural science. The difference reveals itself in what kind of theories (models, methods, etc.) are in the focus for these two contradictory directions. While the university world is focused on theories that are aimed to explain and predict, in the categorization of (Gregor, 2006), the real world needs the theories of design and action, also in the categorization of (Gregor, 2006). The paper also suggests that the IS discipline needs to take the same path as medicine, engineering and architecture to become useful and relevant to the real world. 
The findings of (Lee, 2010) are in full accordance to what our students do after their graduation. The large majority of them never do any social science type of investigations; instead, their tasks include, diagnostics, analysis, problem solving and design (which is apparent from what positions they take after their graduation according to our alumni survey). Thus, the theories they need are the theories of design and action. That said, teaching the latter just as theories is not enough to attain our goal of students acquiring skills of research-oriented practical problem solving. Some of the students' complaints were not about the theories themselves, but about not getting knowledge on applying them to practice. Teaching the latter is much more difficult than just teaching the theories, as it requires the students acquiring tacit knowledge (Polanyi, 1969), or Ways of Thinking and Practicing (McCune \& Hounsell, 2005), and this type of knowledge is difficult to transfer remaining in the classroom environment.

To answer our second question, about how the theories of design and actions should be taught, we need to analyze our programs. As Sweden has adopted the Bologna recommendations, now, the department has three years BS (bachelor) programs and two years MS (master) programs. Adopting Bologna resulted in a substantial change in the programs, as before the adoption, the department had four-year candidate programs, and one year magister programs. The transfer from the Swedish candidate to BS programs resulted in losing one full year (two terms) of studying. The transfer from the Swedish Magister to Master programs was accompanied with enrolling bachelor students with less IT and IS education (including none), which makes the additional year received in the transition to Bologna used for catching up, i.e. giving courses that before belonged to the candidates programs.

Both BS and MS programs are concluded with a thesis (dissertation) course, which is mandatory. For BS programs, this course is a half term long, while for MS programs, this course is one term long (a quarter of the whole education length). Not all students complete this course in time, and many work on their theses after finishing their education and finding a job. Having thesis courses is mandated by the university, thus the department cannot remove them or substitute with some other courses, e.g. a capstone project. This situation, we believe, is typical not only for Sweden, but also for other European countries, but may not be typical for other regions, e.g. U.S. (Karsten et al., 2015) investigated IS master programs all over the world, and found that most of the European programs included a thesis course.

The short length of the programs does not allow introducing an additional course with just one learning goal research-oriented problem solving. Thus, we need to find an already existing course(s) to introduce this goal. Analyzing our programs, we concluded that the primary candidate for this end was the thesis courses in both BS and MS programs. Firstly, these courses are long enough to accommodate such a goal. Secondly, the students are supposed to do field work outside the university walls in these courses. The basic idea here is that the students do some actual work in an organization (private, nonprofit, or public) of the type they will be doing after their graduation, e.g. problem diagnostics, analysis or design.

One issue that needs to be resolved with the idea of using thesis courses is to fulfill the requirement of the Swedish legal framework related to higher education (Higher Education Ordinance), which prescribes the education having both a scientific base, and being related to practice. The risk of the thesis work becoming a consultant work, and the thesis - a consultant report needs to be mitigated. A traditional way of satisfying the requirement on scientific base in a thesis is asking the student to complete a mini-research project, e.g. a short empirical research based on surveys and/or interviews. However, the requirement on scientific base does not limit the ways in which it could be satisfied; other options are open for exploitation. One option that could be satisfactory for both requirements on scientific base and being related to practice is using contemporary research for solving practical problems in an organization to which a thesis work is attached, rather than employing standard solutions already accepted in practice. One can envision various ways of using research in problem solving. For example, one can review several scientific approaches suggested in the literature, choose one, and then report how well it worked in practice. Alternatively, one can pick a new innovative, but not tested in practice, theory or method, and try to apply it to a practical problem.

One question is whether the Swedish organizations are willing to accept the students using research-based solution, instead of more established in practice methods. In our practice, we found that Swedish organizations fully understand the needs for students fulfilling the requirements of a scientific base, and they are content to leave them to test new theories and ideas. This, probably, can be attributed to the fact that the managers, being former university students themselves, perfectly well understand the students' needs to pass their exams. We believe, that there are no hinders to encourage the students to do their thesis work as research-based practical problem solving at an industrial, public, or not-profit organization. 
The goal of our current project is creating methodological support for practically oriented BS and MS thesis work. It aims at designing a set of logical templates and guidelines on selecting among these to be used by supervisors and students whose theses are aimed at solving concrete problems in practice. Under logical template, we understand a thesis report outline with suggestions on sections and subsections headings together with detailed explanations on what should be included in each section/subsection, as well as examples. A template serves as a guideline for both: how to do the work, and how to format the thesis report.

There is a large body of literature devoted to methodological support for thesis writing, including books dedicated to this purpose (Biggam, 2008). However, most of this literature is focused on the thesis being a small research project, rather than research based solving of practical problems in organizations or other societal setting. The literature devoted to practically oriented thesis writing is relatively rare, and mainly concerns doctoral thesis (Archbald, 2010). The recommendations from such literature, though useful, cannot be directly applied to BS and MS theses due to the different time frames for BS, MS and PhD thesis writing. So far, we have not found works related to BS and MS theses that include not only principles, but also logical templates of different kinds that would be suitable for our programs.

Methodologically, our work fits the action research paradigm (Baskerville \& Myers, 2004; Kolb, 1984), as we deal with a problem found in a local (teaching) practice, and we are testing a solution in the same practice. Our research can also be categorized as Design Science (DS) research (Hevner et al., 2004), as we aim at designing a solution (or artefact) in the form of a set of logical templates and rules of how to choose the one that suits best particular business settings.

The rest of the paper has the following structure. We start with literature review. Then, we describe the main ideas of our project. After that, we describe the current state of the project, plans for the future and potential impact of our work on the society in case of success, including accomplishing the third mission.

\section{LITERATURE REVIEW}

\subsection{General Literature on Thesis Writing and Supervision}

The literature on the topic of writing and supervising theses is vast. The literary review (Svärd, 2013) has found more than 200 research articles related to the theme; this number does not include numerous books and manuals with prescriptions on writing thesis and thesis structure. The reviewed literature covers a wide range of topics, such as motivation (including legal issues), completion, disposition, grading criteria, supervision, etc. The conclusion that (Svärd, 2013) draws is that the area is quite researched, but lack of systematization. However, it also underlines that not all areas related to BS/MS thesis are investigated in the same depth. Some relevant for our work areas that lack consensus, or are less investigated are highlighted below.

The research on thesis work is mostly related to professional education, especially in such areas as teaching (see also the next section) and nursing. Some other professions that have research on thesis writing include engineering, business and psychology. (Svärd, 2013) does not mention any works related to Information Systems Education, or Computer Science. This corresponds to our own experience of trying to find research papers on thesis writing in IS.

There is no consensus on the motivation of the thesis work. There are two opinion on the motivation: one is that thesis work should be regarded as preparation for research activity, the second is that the thesis work should aim at preparing students for work outside academia. The discussion on which motivation should prevail is going for several decades without reaching a consensus. The more spread opinion is the research-oriented motivation, though the professional preparedness motivation is also discussed in the literature. For example, (I'Anson \& Smith, 2004), among other rationales for thesis work, include:

- $\quad$ To help the students' ability to define and analyze a complex business problem

- To help students integrate academic knowledge and practical applications

These rationales are in full agreement with our opinion on the thesis work aim.

From the legal perspective, the Swedish legal regulation is considered as not very restrictive, see for example (Gustafsson, 2008) that analyzes the history of regulation in this area. This "elasticity" of regulations is compensated by each Swedish university department choosing to interpret the regulation in different ways dependent on the subject matter, and own preferences. (Gustafsson, 2008) also makes an 
observation that though the regulation does not prohibit practically-oriented thesis, they are not very common, at least in the teachers education. The main reason for this is considered not the regulation as such, but academics themselves "who have an academic tradition and who want to protect the degree project as an academic product." We believe that this also explains the fact that the literature related to practically oriented thesis is not that extensive compared with the literature related to research-oriented thesis.

From the disposition perspective, (Svärd, 2013) states that most common type of thesis is a mini-doctoral dissertation, though alternative forms are also discussed in the research literature. One of this form is a Patchwork Text (Maisch, 2003), or Portfolio (Meeus et al., 2004) where a dissertation consists of an assortment of texts written at different times and connected together in the end. Though this form could be of interest in some fields, we do not believe that it would be beneficial for the practically oriented thesis in our discipline.

As far as books and manuals for conducting thesis work are concerned, they are numerous. However, as (Svärd, 2013) concludes, the great majority of them consider only a research-oriented work formed as a mini $\mathrm{PhD}$ dissertation. This observation corresponds to our own experience when trying to find a proper disposition for practically oriented BS/MS thesis.

\subsection{Literature Relevant to the Topic of Practical Oriented Thesis}

In this section, we review the works which are directly related to our topic, and which discuss not only the needs and ideas of practically oriented theses, but also practical experience of introducing this kind of thesis writing. The best works that we have found that are related to the topic belong to the educational domain (Archbald, 2008; Archbald, 2010; Belzer \& Ryan, 2013). Though these works concern doctoral education, insights from them are highly relevant to undergraduate theses as well.

A seminal work in this area (Archbald, 2008) starts with:

"Although many doctoral mentors doubtless have misgivings about training someone to do research who is not going into professional research, such misgivings have not translated into organized efforts at change or even much public deliberation on the subject"

The paper continues with discussing the four important issues related to doctoral theses: (a) developmental efficacy, (b) community benefit, (c) intellectual stewardship, and (d) distinctiveness in form and function. During this discussion, the paper underlines the difference between the research-oriented and practically oriented dissertations in regard to these issues. For example, while the goal of efficacy with research-oriented dissertations is training in being a researcher, this goal for the practically oriented dissertations is training for the practical purpose, for educational leadership in the particular case taken in the paper. The paper proceeds with pointing out five areas where research and practically oriented dissertation differs:

1. Pragmatic problem, not theoretical question

2. Multiple questions, not a single hypothesis or research question

3. Persuasion, not proof

4. Recommended actions, not conclusions

5. Professional report, not a research monograph

The following work of the same author (Archbald, 2010) discusses the experience of having practically oriented doctoral programs. It points out four major changes that need to be done for transiting from research-oriented to practically oriented dissertations, noting that these changes are not small adjustments, but a radical change that results in breaking the current tradition:

1. Research studies begin with theory, curiosity, and questions. The topic and research question is based on studying the literature and identifying a gap in theories. In real-world practice, problems do not present themselves to the practitioner as givens. The candidate must construct a problem definition, defining a gap between an existing state in an organization and a preferred goal state.

2. The literature review in a traditional thesis is presented in a chapter. In a practically oriented thesis, according to (Archbald, 2010), it should be used in any place of the text as needed.

3. In a research thesis, the epistemology and methods of science govern the collecting, reporting, and interpretation of evidence. The new type of theses reflects an epistemology of decision-making. This statement corresponds to the difference between usage of theories for explaining and predicting on the 
one hand and theories for design and actions, in the categorization of (Gregor, 2006) on the other hand, which was discussed in the previous section.

4. A research dissertation is aimed at generation of new knowledge to be presented to the examination committee, which serves as a proxy for the larger scholarly audience. The new thesis compiles scholarly narrative along with documents for organizational audiences and other artifacts generated as part of the problem solving initiative.

(Belzer \& Ryan, 2013) summarizes the experience of practically oriented dissertation programs at School of Education at Rutgers focusing on which kind of problems are to be handled in the practically oriented dissertations. In their practice, the three types of practical questions are most common: "(1) questions that evaluate an initiative or policy that is already in place, (2) questions that ask what happens when the student implements an initiative to solve a problem and improve outcomes, and (3) questions that seek to describe current conditions as a way to generate appropriate and contextualized solutions to problems". All three correspond to the recommendations in a handbook they created for the program.

(Mason et al., 2015) presents an experience of making dissertation relevant in Lamar University. Besides the issues discussed in other works, this paper discusses support the university provides in offering doctoral candidates opportunities to team with organizations throughout the world in order to affect change and impart relevant impact on education and communities.

\section{OUR APPROACH}

The literature reviewed in the previous sections gives insights in the issues to be resolved when transiting from research-oriented to practice-oriented dissertations. However, the experience presented in this literature cannot be directly applied to our BS and MS programs without adaptations. Firstly, our programs are in another domain in which the students work with both organizational and technological issues, and often a combination of both. Thus, practical problems can be connected to system design and implementation in organizational practice. Secondly, and more important, the time frame of a BS and even MSc thesis course radically differs from the $\mathrm{PhD}$ study.

In principle, the easiest way of introducing practically-oriented thesis in the IS discipline while formally remaining in the research domain would be forming the work according to the Action Research (AR) (Baskerville \& Myers, 2004) or Design Science (DS) (Hevner et al., 2004) paradigm. The latter was what we tried in our department by creating a template for DS based theses. However, due to the short time frame even for the MS thesis work, this template did not work well, as it required to address all parts of the DS process, while a student, usually, could be able to complete only one or few of them. The template created unnecessary formalities that distracted and confused the students. We did not try to make an AR template, as the chances that a student can complete even half of the AR cycle are slim. Based on the experience of using the DS template, we decided to create a set of less bureaucratic templates, each of which covers a specific type of the thesis projects.

For developing new templates, we assume that the settings for a practically oriented BS or MS thesis are as follows. The work is connected to an organization that provides the student with access to the information related to the organization's business and its technological infrastructure. Such access consists of possibility to interview the staff of the organization and/or conduct a small-scale survey, read internal documentation, including documentation on their IT systems, observe how the staff works, e.g. by being present at the internal meetings. We also assume that the students have a possibility to present the results of their work to the management and other workers involved in the area of thesis work, and get feedback on the usefulness of these results.

To satisfy the requirement on having both scientific and practical content, we consider two dimensions in order to create a general classification of thesis work: (1) business dimension and (2) theoretical dimension. The business dimension is related to whether the organization wants the student to deal with a particular problem they want to solve, or challenge to meet, or they allow him/her to freely choose what to focus one. This dimension is about the problem uncertainty. The theoretical dimension is related to whether the student has a preference to certain theories, methods, modeling techniques, etc. that s/he wants to test, or these need to be found during the work on the thesis. This preference can come from the student's own interests, advice from the supervisor, or even from the organization to which the student work is attached. Combining the two 
dimensions, we get a classification of the thesis works as represented in Fig. 1. Note that term theory in this picture is interpreted in a broad way; a theory can be a specific modeling technique, or some kind of a method.

The classification in Fig.1 defines a starting point for the student work, which can be of three types, explained below:

1. Testing a specific theory, method, modeling technique, etc. for solving a specific problem or meeting a challenge. The task here could be to identify the underlying cause of the problem (diagnostics) and/or suggest a solution. The outcome can be both positive, the theory has been found suitable or not suitable for solving this kind of problems. The theory, method, or modeling technique used should be somewhat innovative, e.g. new, or not much tested for this specific problem-solving.

2. Finding a theory method, modeling technique, etc. for solving a specific problem or meeting a specific challenge. The focus here is to complete the task of the same kind as in quadrant one while finding a suitable way of doing so. The outcome is to be positive, i.e. the task completed is by the end of the thesis.

3. Having an interesting, and innovating theory, method, modeling technique, etc. find out what can it be used for in an organization. It could be a completely new theory, or a student will try to find an unusual usage of the known theory.

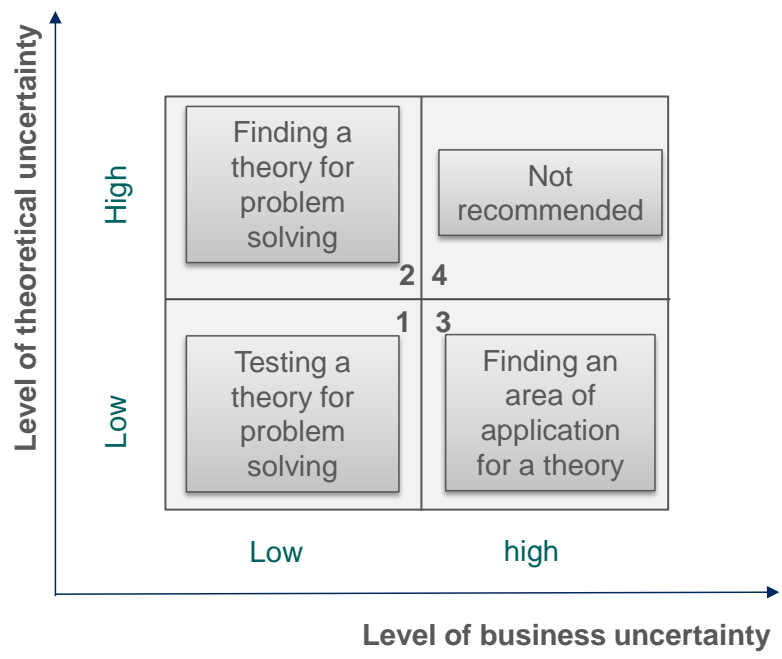

Figure 1. Classification of Thesis Types

The fourth type is not recommended due to the short timeframe for completing the work; a student needs to have a more definite starting point for his/her work then just having an organization to be attached to. Also, the starting point does not preclude changing to another quadrant after the work has already been started. For example, a student starting in quadrant one can discover at an early stage that the original theory does not suit the task, and transits to quadrant 2 in order to complete the task, not just report on the unsuitability of the original theory. As another example, a student starting in quadrant 3 can early in his/her work find a particular problem to work on and switches to quadrant 1 to continue his/her work.

To illustrate Fig. 1, below, we give one example of MS thesis for each of the recommended quadrants:

1. Business context is an IT consulting company. Business problem is to analyze external and internal communication in the frame of a business process and find areas for improvement. Theoretical foundation is a LAP-based (LAP = Language Action Perspective) methodology developed for analyzing communication capabilities of business process support systems (Bider, 2015). This framework had never been tried for analysis of communication as such. The thesis work included adjusting the framework to the new task, conducting interviews, completing analysis of communication in one of the processes and presenting the findings to the management. The findings included a list of areas for improvement and some suggestions. 
2. Business context is a manufacturing company. Business problem is a dysfunctioning business process of producing a sample of a new material on the request of an existing customer. The company discovered that the time for completing such a request started to grow, which was not appreciated by the customers. The work included finding the cause and suggesting a way to optimizing the process. First, the company wanted the student to use a specific method for the task, but agreed to allow the student to freely choose any method(s) that would be found suitable. The students conducted a field study and applied several methods for analyzing and interpreting the material, two of which were taken from the latest research publications (on the advice of the supervisor). The main problem with the process was defined as the process not having dedicated resources, e.g. people, machines, materials, but using resources dedicated to the production process in an ad hoc manner. One of the technique used for interpreting the material showed exactly what resources where shared between the processes, and what was lacking. The results were presented to the company management, who said that they had had some suspicion that there is a managerial problem, but did not now it for sure.

3. Business context is an IT solutions provider. Theoretical background is a new technique for enterprise modeling (Bider et al., 2017). The task is to discover new areas of application for the technique. An approach taken in the thesis project was to build a model that would cover some important parts of the enterprise, and then to present it to the employees with different roles and ask these for what purpose(s) the model could be used. The company agreed to provide resources (people to interview and observe, documentation, etc.) for the study, even though it was not aimed at solving a specific problem. The model was built and presented, and very interesting for farther research feedback was obtained.

\section{CURRENT STATE, PLANS FOR THE FUTURE AND POTENTIAL IMPACT}

Our work on methodological support for practically oriented theses started at the end of 2015 and was completed on the basis of an individual initiative in spare time. We created a set of logical templates and short guidelines for how to choose a suitable one base on the case in question in the form of a decision table (Bider, 2016). The templates were published on the thesis course website with recommendation for the supervisors to use them when the thesis is related to a case in practice. The templates and guidelines were used in our own practice and by some other teachers who considered them useful. Besides using the templates to organize the students work and the structure of the thesis, the templates were used as a means for communication between the teaching staff engaged in the thesis work: Supervisor-Reviewer-Examiner.

As the project had been started based on personal initiative, there were no dedicated resources attached to it. Templates and guidelines, though useful, have never been modified/extended/streamlined based on the practice of their usage. Also, designing the templates was not coordinating with adjusting the grading criteria and methodological courses, of which we had more than one. This resulted in the templates we created having historical traits of the old thinking - considering a thesis as a mini research. The historical traits and the old-style methodological courses resulted in some confusion among students, which created an additional burden for the supervisors. In addition, no investigation of the impact of the new thesis types on the students learning has been made, and no efforts to promote them among all supervisors have been undertaken.

For the future, we plan actions aimed at moving the project beyond being the individuals' initiative to becoming part of the strategy of improving the education in the department. In particular, the activities listed as not completed at the end of the previous section need to be completed, e.g.:

- Based on the outline presented above and experience of template usage correct, streamline and extend the existing set of templates. Classification from Fig. 1 could be employed for this end.

- Investigate the impact on students learning through surveys/ interviews with current and former students.

- Adapt grading criteria and scientific writing and methodology courses to include the new type of thesis.

- Introduce a new method course aimed at preparing the students for writing practically oriented thesis.

The decision on this issue has already been taken and the work is about to start in spring 2019.

These activities are aimed at making the theses of the research-oriented problem solving type well established in the department. 
Besides attaining our main goal stated above, we believe that introduction of the practically oriented type of thesis can assist in accomplishing the university's third mission: (a) targeted use and transfer of academic knowledge to help resolve diverse societal challenges, and (b) transfer of technologies and innovations in the form of cooperation with public and private enterprises. Firstly, the academic staff, as students' supervisors, will be directly involved in solving practical problems advising the students on what theories and methods to choose, including those that are worked out by the supervisors themselves. Secondly, the students who have acquired the research-oriented problem solving skills during the thesis course will be able to use these skills after graduation, if not immediately, then after achieving a more independent senior position in their future careers. This can multiply the efforts of our academic staff, and, hopefully, lead to the usage of research-oriented problem solving becoming a norm in practice, rather than an exception.

\section{REFERENCES}

Archbald, D., 2008. Research Versus Problem Solving for the Education Leadership Doctoral Thesis: Implications for Form and Function. Educational Administration Quarterly, 44(5), pp.704-39.

Archbald, D., 2010. "Breaking the Mold" in the Dissertation: Implementing a Problem-Based, Decision-Oriented Thesis Project. The Journal of Continuing Higher Education, 58, 58(2), pp.99-107.

Baskerville, R. \& Myers, M.D., 2004. Special Issue on Action Research in Information Systems: Making IS Research Relevant to Practice-Foreword. MIS Quarterly, 28(3), pp.329-35.

Belzer, A. \& Ryan, S., 2013. Defining the Problem of Practice Dissertation: Where's the Practice, What's the Problem? Planning and Changing, 44(3/4), pp.195-207.

Bider, I., 2015. Analyzing communication capabilities of CM/ACM systems with the help of Language/Action perspective. In L. Fischer, ed. Thriving on Adaptability: Best practices for knowledge workers. Future Strategies Inc. pp.88-99.

Bider, I., 2016. Choosing Template. [Online] Available at: http://bit.ly/2TfPice [Accessed February 2019].

Bider, I., Perjons, E., Elias, M. \& Johannesson, P., 2017. A fractal enterprise model and its application for business development. Software \& Systems Modeling, 16(3), pp.663-89.

Biggam, J., 2008. Succeeding with Your Master's Dissertation. A step-by-step handbook. Open University Press.

Gregor, S., 2006. The Nature of Theory in Information Systems. MIS Quarterly, 30(3), pp.611-42.

Gustafsson, C., 2008. Degree Project in Higher Education. In M. Mattson, I. Johansson \& B. Sandström, eds. Examining Praxis. Rotterdam: Sense Publishers. pp.7-34.

Hevner, A.R., March, S.T. \& and, P.J., 2004. Design Science in Information Systems Research. MIS Quarterly, 28(1), pp.75-105.

I'Anson, R.A. \& Smith, K.A., 2004. Undergraduate Research Projects and Dissertations: issues of topic selection, access and data collection amongst tourism management students. Journal of Hospitality, Leisure, Sport \& Tourism Education, 3(1), pp.19-32.

Karsten, H. et al., 2015. Master's Degree Programs in Information Systems: A Global View. In SIGED: IAIM Conference. AIS.

Kolb, D.A., 1984. Experiential learning: Experience as the source of learning and development. Englewood Cliffs, NJ, US: Prentice-Hall.

Lee, A.S., 2010. Retrospect and prospect: information systems research in the last and next 25 years. Journal of Information Technology, 25, pp.336-48.

Maisch, M., 2003. Restructuring a Master's Degree Dissertation as a Patchwork Text. Innovations in Education and Teaching International, 40(2), pp.194-201.

Mason, D., Shelton, S. \& Saltsman, G., 2015. Making the doctoral dissertation relevant. In The meeting of the National Council for Professors of Educational Administration (NCPEA). Washington, DC.

McCune, V. \& Hounsell, D., 2005. The development of students' ways of thinking and practising in three final-year biology courses. Higher Education, 49(3), pp. 255-289.

Meeus, W., Van Looy, L. \& Libotton, A., 2004. The Bachelor's thesis in teacher education. European Journal of Teacher Education, 27, pp.299-314.

Polanyi, M.S., 1969. Knowing and Being. Chicago: University of Chicago.

Simon, H., 1969. The Sciences of the Artificial. Cambridge, MA: MIT Press.

Svärd, O., 2013. Examensarbetet i högre utbildning: En litteraturöversikt. Pedagogical Research in Uppsala, No 165. Uppsala : Uppsala University Institutionen för pedagogik, didaktik och utbildningsstudier. 